\title{
Differentiating outcomes in children living in non- kinship and grandparent kinship care homes
}

\begin{abstract}
Seldom do public health professionals consider topics such as foster care and the health outcomes associated with it. On the surface foster care is simply another person or entity caring for a child, sometimes for financial gain depending on the type of care. Foster is defined as assuming the responsibilities of primary or temporary custody. Kinship care is the full time care, fostering and sheltering of children by relatives, members of their tribes or clans, godparents, stepparents, or any adult who has a kinship bond with a child. ${ }^{1}$ Many children are removed from homes and are court ordered to outside dwellings to reduce neglect, abuse, domestic violence, and environments that foster risky behavior such as drugs and alcoholism. Children residing in unrelated foster placements were considerably more likely to have been recorded as having experienced emotional difficulties, such as anxiety and depression. ${ }^{2}$ The Healthy Grandparents Program was curious about which type of care is more effective, with respect to, child outcomes in academics, cognitive development, and physical disabilities. The Healthy Grandparents Program is not based off a certain theory it is more of a directional program that guides the grandparents in the right direction so that their grandchild will be taken care of on all levels financially, educationally, and socially. Research explained foster care is public health and its influences in our society need to be observed more to provide a healthier and safer city, state, country, and world. Foster care impacts socio-economic status, cognitive development, and chronic illnesses among our children and children are our future.
\end{abstract}

Keywords: public health professionals, child welfare, kinship, non kinship
Volume 3 Issue I - 2015

\author{
Norman Hart BS \\ Degree of Master of Public Health, Mercer University School of \\ Medicine, Georgia
}

\begin{abstract}
Correspondence: Norman Hart BS, Degree of Master of Public Health, Mercer University, School of Medicine, Macon, Georgia, Email nhartiv@gmail.com
\end{abstract}

Received: June 24, 2015 | Published: December 03, 2015
Abbreviations: CWS, child welfare system; VA, veterans affairs; TANF, temporary assistance for needy families; NSCAW, the national survey of child and adolescent well-being; ADHD, attention deficit/ hyperactive disorder; DCSF, department for children, schools and families

\section{Introduction}

Typically public health is concerned with the impacts of diabetes, obesity, and HIV or the spread of diseases. Seldom do public health professionals consider topics such as foster care and the health outcomes associated with it. On the surface foster care is simply another person or entity caring for a child, sometimes for financial gain depending on the type of care. Foster care can result in various outcomes and impacts families dramatically. Terms like kin care (kinship), non-kin care (non-kinship), unrelated and related care are used simultaneously to refer to foster care. Foster is defined as assuming the responsibilities of primary or temporary custody. Kinship care is the full time care, fostering and sheltering of children by relatives, members of their tribes or clans, godparents, stepparents, or any adult who has a kinship bond with a child. ${ }^{3}$ Non-kinship foster care is custody over a child with no relation by blood or kinship bond to the fostering parent or guardian. Many children are removed from homes and are court ordered to outside dwellings to reduce neglect, abuse, domestic violence, and environments that foster risky behavior such as drugs and alcoholism.

Foster care is a serious matter and a significant public health issue. "Children placed in foster care have typically experienced maltreatment in the form of physical, sexual, emotional, or psychological abuse, and general neglect". ${ }^{4}$ Foster care affects both the child and the parent. In particular, it affects a child's cognitive and emotional development negatively or positively, up to $80 \%$ of children in foster care have serious emotional problems, and almost half of the children have developmental delays. ${ }^{5}$ Foster children also tend to have chronic medical conditions; these conditions could be internal illnesses or physical disabilities. Mental, Physical and chronic health illness have the potential to effect the child's academics, and the children may become more susceptible to participating in risky behaviors, which creates a number of future health disparities. In 2011, more than half of the children in foster care were children of color. Approximately, $27 \%$ of the children of foster care were African American, which is double the population percentage of African Americans in the United States. ${ }^{5}$ Kinship care specifically grandparents is a positive approach for foster children because the relative knows their situation and is less likely to judge the child, compared to someone who has no relationship to the child.

\section{Literature review}

A literature review was conducted regarding, grandparent care versus non-kinship foster care, and to examine which care is more effective for the child. As specified earlier, foster children endure many adversities throughout their lives. The term adversities in the case of foster children describes the hardships they've experienced such as neglect, child abuse, sexual abuse, and maltreatment. Foster children may be challenged by adversity from their birth parents or foster parent. "Many children in the child welfare system (CWS) have histories of recurrent interpersonal trauma perpetrated by caregivers early in life often referred to as complex trauma". ${ }^{6}$ Complex trauma 
is a word used to define symptoms of adversities suffered by foster children such as damage to a child's emotions, behavior, interpersonal thinking, physiological, and cognitive functions. The CWS conducted a study regarding, methods that reduced the number of complex trauma illnesses suffered by the foster children. ${ }^{6} \mathrm{CWS}$ used adult mentors to communicate with the foster children, a decision based on previous research showing that children were more receiving of an adult mentor rather than their foster parent. The children were given the opportunity to converse and express their true feelings to someone who would not judge them. The CWS found this method was effective to and would assist in reducing foster children adversities. ${ }^{6}$ Essentially, CWS found that adversities were reduced when children were given the opportunity to talk to and express their feelings to an adult who was not their foster parent because such an adult was considered to be more non-judgmental.

Another study conducted by the Tyler and Melander at the University of Nebraska, found that foster children who were not monitored for long periods of time by their parents were more likely to participate and become more involved in daily activities and conversations. They found that giving the child more freedom provides the child with an opportunity to become more open with their feelings, and the child is less likely to have emotional or psychological stress.

The purpose of this project is to differentiate between grandparent care of foster children and agency care of foster children. The Healthy Grandparents Program was curious about which type of care is more effective, with respect to, child outcomes in academics, cognitive development, and physical disabilities. The Healthy Grandparents Program is not based off a certain theory it is more of a directional program that guides the grandparents in the right direction so that their grandchild will be taken care of on all levels financially, educationally, and socially.

\section{Goals and aims}

The purpose of this project is to define the differences between grandparent care of foster children and care by foster parents or agencies. The Healthy Grandparents Program would like to assess the outcomes concerning the children's academics, participating in risky behaviors, cognitive development (ADD, ADHD), and physical disabilities. Based on findings, the Healthy Grandparents Program will reassess its program curriculum to improve its services for the grandparents and their grandchildren, so the program can have an even greater positive effect on its communities. Being that the program is grant funded, it will use this project opportunity to apply for grants, to increase its amenities and financial assistance for the participants and their families.

\section{Methods and procedures}

\section{Project Design}

In order to assess and achieve the overall goal of this project, qualitative and some quantitative data will be collected and has already been collected from past program participant updates from active grandparents in the program. An interview tool will be used to assess half a dozen active participants in the Healthy Grandparents Program. Some interviews will be conducted face to face and others will be over the phone.

\section{Setting}

The project will take place at Georgia Regents University, in the Healthy Grandparents Department which is located inside the university nursing school, but research can be done on site or in alternate area where materials are available.

\section{Participants}

Healthy Grandparents is a one year program but many of the participants continue to be involved and remain active in the program due to its positive impact. The average age of grandparents in the program is approximately, the oldest grandparent in the program is 82 years old and the youngest grandparent is 39 years old. There have been 181 single grandmothers, 2 single grandparents, and 107 married couple to enter The Healthy Grandparents Program. Most participating grandparents are primarily Black/ African American, and live under the poverty line. About $69 \%$ of the grandparents' household income is from employment, retirement, or Veterans Affairs (VA). Of the families ever enrolled in the Healthy Grandparents Program, $42 \%$ have been provided government food stamps. Almost $50 \%$ of grandparents in the program are unemployed. Only $36 \%$ of grandparents receive income from retirement/ social security. About $48 \%$ of households in the program are assisted through Temporary Assistance for Needy Families (TANF). "From 2008 to 2009, for every 100 Georgia families living in poverty, only 8 received TANF benefits". ${ }^{3}$ Roughly, $11 \%$ of families have received child support. Throughout the program's existence it changed the lives of over 668 children, but $57 \%$ of these children have been diagnosed with a mental, physical, and or neurological issue. Approximately 353 children (53\%) of children currently or prior enrolled in the program have been exposed to drugs and alcohol. The program provides adequate assistance for these children, need it be counseling, mentoring, or a health related issue, and they direct the grandparent into the best situation for their family. There is also a monthly support group in which a speaker from the community, policy maker, or even a past grandparent from the program will come to encourage or update the grandparents on different opportunities for them and their children, these opportunities could be financial, educational, spiritual, and health related.

\section{Budget}

This project was of no cost. Each interview was administered for free. All materials for this project were provided and or developed at no cost. The Preceptor was very open and accommodating, and stated e if any items were needed to inform him and he would provide them.

\section{Instrumentation}

The instruments that will be used in the project will be an interview questionnaire, past data collected since the existence of the program which was established in 1999, and data collected through research of foster care and grandparent care.

\section{Data collection}

Data collection will begin with the data already collected from past participant reports. Data will also be collected through one-on-one interviews and phone interviews with grandparents who are active in the program. Other data will be collected through computer research, of grandparent care and state agency foster care.

\section{Results/Outcomes/Tangibles}

The Healthy Grandparents Program has a monthly support group meeting on the last Tuesday of each month at 10a.m. and 6p.m. on site at Georgia Regents University in the school of Nursing. I attended the meeting in March where I conducted face to face interviews. Others 
interviews were conducted over the phone. After, interviewing a few grandparents I learned that their grandchildren suffer from some of the same problems such as health conditions, mental conditions, and even academic struggles. The age of the kids ranged from 1 to 17 years old and the average age of the grandparent was 58years old. These grandparents had been caring for their grandchildren for an average of about 9years. I asked each person interviewed how he or she heard about the "The Healthy Grandparents Program." My preceptor was also interested in how most of the grandparents in the program where informed about it. Each grandparent interviewed except for one because she was an employee of the Georgia Regents University, stated they heard about the program through word of mouth from another grandparent. I also asked would they like to see any changes in the program. I received a few different responses. The most common answer to that question was that they would like for more grandparents to be more active in the program so that it may grow at a faster rate. Another answer I received was that she wanted to receive more financial assistance, so that her family could maintain a healthier stable living environment. I also noticed that some participants were not as open with their answers as others. Financial assistance is not awarded to the grandparents as it is for a foster parent with a state agency. Agency foster care parents have a better opportunity of being financially stable because they are compensated for the children they receive. The cost of a foster child per year was an additional issue my preceptor was interested in, so I asked my participants that question during the interview. I received amounts ranging from $\$ 5000-\$ 30000$ which were much lower than the average cost per year for a child in foster care according to the North American Council on Adoptable Children, which is $\$ 35,600$. After hearing these responses I knew they were not receiving financial assistance for foster care. The project results are more so qualitative data, than quantitative data.

\section{Discussion}

In Georgia 301,254 children under the age 18 live in homes where the householders are grandparents or other relatives. Of those children, 39\% $(116,071)$ live in homes where grandparents are held solely responsible them (AARP, 2013). There are over 102,000 grandparents in the state of Georgia that care for their grandchildren solely (AARP, 2013).Precisely 399 grandparents have been served by the Health Grandparents Program since its establishment. As stated earlier children in foster care often face some sort of adversity with respect to maltreatment, neglect, and abuse physically, emotionally and psychologically. Grandparents take on the challenge to raise their grandchildren in spite of the child's physical, psychological, or emotional state of mind. Child abuse and child neglect are hidden epidemics in the United States, yet 6 million children experience some type of abuse. Every 10 seconds there is a report of child abuse in the United States. ${ }^{1}$ Particularly in the state of Georgia there were over 38,000 reports of child abuse. ${ }^{3}$ Approximately 26, 011 reports were investigated, this creates a possibility of almost 30,000 children becoming enrolled in the foster care system, and at least $50 \%$ of them would be in kinship custody. ${ }^{3}$

Becoming enrolled in foster care interrupts a child's development emotionally, and behaviorally, and it also may affect the brain's development. ${ }^{4}$ The development of a child's brain is essential to its growth and progress throughout life psychologically; foster children are at risk for a variety of mental health problems. The National Survey of Child and Adolescent Well-Being (NSCAW) sampled 6200 children and families in the welfare system of the United States, nearly half of the children sampled showed signs of emotional and behavioral problems. ${ }^{4}$ In another, study conducted by NSCAW among 5-9-year-old children in out-of-home care, $49 \%$ of them had psychiatric disorders such as, depression, conduct disorder, and attention deficit/ hyperactive disorder (ADHD) and all had been abused. ${ }^{4}$ These disorders lead to other adversities for the child such as placement disruption, where a child is placed in more than one home throughout its time in foster care. "Foster children are also at elevated risk for disruption in key areas of brain development". ${ }^{4}$ Foster children may not only have delayed growth of the brain but could possibly begin to process daily activities slower than the average child. In a study, that involved foster children reared in low-income, non-maltreating biological families, the children experienced deficits in various cognitive functions, including poorer memory skills, lower scores on intelligence tests, and less developed language skills. ${ }^{4}$ The low socio-economic status of the foster children damaged their brains on many levels; today the discussion about low socio-economic status is a key topic, in public health. The study identifies poor performance in school and constant cognitive delays as issues.

The Department for Children, Schools and Families (DCSF) funded a study, using a catch-up prospective design based on a cross section of children in England who were in kin and unrelated foster care placements, on a specific date so the participants could be followed for up to a period of 2 years. ${ }^{2}$ The catch-up prospective design is a retrospective study which is used to conduct follow ups. The study was conducted on 4 local foster care authorities in England all of which had a high volume of black minority children, 3 of the local foster authorities reported a list of the children who were in kinship care homes. ${ }^{2}$ Thirty- two families including parents and children were interviewed along with child's case workers. These interviews provided the study with adequate information, pertaining to kin care and non-kin care, but some data was not routinely recorded due to certain issues. ${ }^{2}$

Through these interviews they discovered a number of similarities and few differences. The DCSF learned that the children experienced the same adversities such as neglect and child abuse before placement. There were no differences in long term health problems, or educational needs, however. Both kinship care children and non-kinship care children exhibited behavioral problems in home care and out of home care before becoming permanently placed. The Journal Family Process explains children in foster care "silently hold their difficult thoughts and feelings, frequently resulting in increased behavioral problem" and that when foster children do so they are less likely to anger or hurt their foster parent emotionally (Linares, Rhodes, and Monalto, 2010). Children residing in unrelated foster placements were considerably more likely to have been recorded as having experienced emotional difficulties, such as anxiety and depression. ${ }^{2}$ The literature states the social workers involved in the interview process did not have adequate information on children in related foster care homes; this information drastically affects the outcome of the research conducted.

According to the DCFS measured the number of adversity outcomes experienced related foster care children and unrelated foster care children was similar, but children in non-kinship care had slightly more adversity outcomes than children in kinship care. One key adversity explained in research was children raised by both parents at birth were more susceptible to being placed in unrelated foster care, which differs from children in related foster care, because they were raised by one parent before being placed in foster care. After assessing the data collected on adversity outcomes, over $50 \%$ of both children in non-kinship care and kinship care had experienced domestic violence before being placed in out of home care. ${ }^{2}$ Another 
considerable contrast is children with chronic medical conditions were more likely to be placed in non-kinship care foster home, when compared to children in kin care foster homes.

The article then goes into the comparison and contrast care of children from a non-kinship foster parent and a kinship foster parent. Grandparents were the highest amongst kin care foster parents at $45 \%$ followed by aunties at 32\%. Ex-residential workers, former step-parents, and even teachers accounted for $18 \%$ of non-kinship care foster parents. Most kinship care foster parents were lone cares single women that initially lived in overcrowded conditions. Other kinship foster parents may experience chronic illnesses, disabilities, and financial hardships. The average age of a kinship foster parent in this study is 57 years old, the parent ages ranged from 35 to 82 years of age. ${ }^{2}$ These kinship care foster parents experience overcrowding in their homes especially when fostering involves siblings. The older age of kinship foster parents makes them vulnerable to health difficulties and illnesses, at least a third of kinship care foster parents suffered from an illness. If these sicknesses became life threatening other relatives would step in to resume care of the child.

As care relates to finances kinship care foster parents do not receive as much financial assistance as non-kinship foster parents. Local fostering authorities pay kinship foster parents an allowance but do not include clothing, holidays, birthdays, and Christmas. Nonkinship foster parents receive funds for all occasions. Some kinship foster parents have maintained their circumstances but only if they were parenting for more than one child particularly siblings. A child with special needs is more expensive than the average foster child but kinship foster parents are still allocated the same funds as if the child was average.

\section{Conclusion}

In conclusion, children in kinship care foster homes may have experienced some crowding; or financial support was not as enough to provide the child with a healthier stable environment. Both kinship and non-kinship foster children experienced some type of neglect or abuse that created mental interruptions and emotional breakdowns. The final results explains the stability in home care and long term plans for children in kinship care homes are more effective in the foster children's lives because the child does not move around from family to family, they live with one family. ${ }^{2}$

Considering the topic chosen to research, information specifically about non-kinship care versus kinship was limited. Foster care solely provided numerous articles, qualitative and some quantitative data. Current articles printed for this topic were challenging to find, many times I had to link information and articles together. Research conducted on this topic seemed to be done in the late 1980's to the mid to late 1990's. Specific data from local and state agencies were difficult to collect as well because privacy factors must be maintained for the children. Kinship foster care and non-kinship foster care were very interesting subjects. The information provided in this paper broadened my knowledge in public health knowing that public health not only involves obesity, chronic illnesses, HIV, or even environmental hazards. Foster care is public health and its influences in our society need to be observed more to provide a healthier and safer city, state, country, and world. Foster care impacts socio-economic status, cognitive development, and chronic illnesses among our children and children are our future ${ }^{7-15}$ (Appendex A, B \& C).

\section{Acknowledgements}

None.

\section{Conflict of interest}

The author declares no conflict of interest.

\section{References}

1. Child help. 2013.

2. Georgia's children 2012. 2012.

3. Grandfacts. 2010.

4. Goyer A. Raising grandkids: legal issues. 2011.

5. Greeson J, Briggs E, Kisel C, et al. Complex trauma and mental health in children and adolescents placed in foster care: Findings from the national child traumatic stress network. Child Welfare. 2011;90(6):91108.

6. Facts about foster care. 2006.

7. Farmer E. How do placements in kinship care compare with those in non-kin foster care: placement patterns, progress and outcomes. Child and Family Social Work. 2009;14(3):331-342.

8. Kinship care: Fact sheet. 2013.

9. Leve L, Gordon H, Chamberlain P, et al. Practitioner review: Children in foster care-vulnerabilities and evidence-based interventions that promote resilience processes. The Journal of Child Psychology and Psychiatry. 2012;53(12):1197-1211.

10. Lewis C. Providing therapy to children and families in foster care: A systematic-relational approach. Family Process. 2011;50(4):436-452.

11. Statistics for Richmond County. 2013.

12. This is a better way-executive summary. 2013.

13. Williams C. Mentoring and social skills training: Ensuring better outcomes for youth in foster. Child Welfare. 2011;90(1):59- 74.

14. Windsor J, Wing C, Sebastian K, et al. Effect of foster care on young children's learning. Child Development. 2011;82(4):1040-1046.

15. Winokur M, Holtan A, Valentine D. Kinship care for the safety, permanency, and well-being of children removed from the home for maltreatment. Cochrane Database Syst Rev. 2009;(1):CD006546. 